\title{
Negotiated Environmental Governance in The Netherlands: Logic and Illustration
}

\author{
Maarten J. Arentsen
}

\begin{abstract}
The Dutch consensus oriented model of negotiated environmental governance enjoys increasing popularity within the European Union because of its seemingly effective way of dealing with environmental problems. A closer look at the model does not reveal any better performance than European average. The article theoretically explains the strengths and weaknesses of the Dutch model as an iterative policy model in which three different modes of governance-competitive, cooperative, and authoritative-interact and compete to achieve effective efficient and legitimate policy results. The argument is empirically illustrated with findings of energy saving policies in the Netherlands.
\end{abstract}

Cooperation and consensus-building through negotiation underlies the corporatist mode of governance in the Netherlands. This model has its roots in the 18th century and developed within a strong tradition of social engagement and building a strong state (van Waarden, 1992). During the postwar period, classical corporatism was the driving force behind the rebuilding of the country, and it sowed the seeds of economic prosperity and social welfare harvested some decades later. Dutch corporatism came under attack during the late 1960s and early 1970 s in the general wave of social upheaval experienced in many West European countries at that time. The decline of the Dutch pacification model was reinforced by processes of secularization, polarization, and politicization. Leftwing politicians refused to participate any longer in the traditional Dutch corporatist model and redefined the rules of the consensus game (Van Putten, 1992). With a few exceptions (e.g., in the agricultural community), classical Dutch corporatism disappeared, but its heritage still underpins governance in the Netherlands: It lies at the core of socioeconomic policymaking, it guided the process of liberalization of the Dutch electricity market, and it became the dominant mode of governance in Dutch environmental policy.

Abroad, the voluntary and nonforcing manifestation of Dutch environmental policymaking became one of the striking and often celebrated features of Dutch environmental policy. Non-Dutch became more and more curious about the Dutch "management" of environmental issues-public and private actors jointly debating environmental policies; advisory boards, representing different interests, recommending on environmental issues, at the same time accounting for diverse interests; and private actors committing themselves to environmental objectives by means of voluntary agreements, and pursuing, in close harmony and cooperation with public agencies, improvement of the quality of the natural environment. Particularly, non-Dutch became fascinated by the voluntary agreement, and initiated, at least in the European Union (EU), enough curiosity to start exploring the potential of this policy tool in more detail. However, a closer look at the actual environmental performance in the Netherlands reveals a more ambiguous picture. Although there is an ambitious nationwide environmental program consisting of an interrelated set of goals and 
backed by the commitment of almost every industrial sector, the results of this program lead one to be less optimistic. In general, Dutch environmental performance is not significantly better or worse than the average performance in the EU.

This article attempts to address the strengths and weaknesses of negotiated environmental governance by analyzing its underlying logic. It will be argued that Dutch-negotiated governance can be understood theoretically as an iterative process in which three different modes of governance-competitive, cooperative, and authoritative-interact and compete to achieve effective, efficient, and legitimate policy results. As a consequence, negotiated governance reflects the strengths and weaknesses of each of its constituent parts. Its success depends heavily on the ability to maneuver around the dynamic balance between the three modes of governance to improve environmental quality (effectiveness) while taking account of social and economic interests (legitimacy and efficiency). From this perspective, negotiated governance in the Netherlands implies not only bargaining on environmental standards, but also a strategic mix of regulations to improve environmental performance.

Recent trends in institutional political theory (March \& Olsen, 1995; Ostrom, 1986), organization theory (Thompson, Francis, \& Michel, 1994), and neoinstitutional economics (North, 1990) are most helpful in analyzing the underlying logic of negotiated governance. The theoretical argument developed below attempts to integrate the theoretical ideas provided by these different disciplinary traditions. It will be argued that public authorities aiming at environmental goal attainment have to account for their regulatory position in regard to private and other actors, each with their own strategies and agendas. From that it will be asserted that the Dutch mode of environmental governance focuses on legitimacy to be effective in environmental goal attainment. Below these arguments are illustrated tentatively by Dutch carbon dioxide $(\mathrm{CO} 2)$ and energy-saving policies for industry.

\section{An Institutional Rationale of Governance}

According to Rhodes, "The term 'governance' is popular but imprecise" (Rhodes, 1996, p. 652). He distinguishes six different uses of the concept and stipulates "that governance refers to self organizing inter-organizational networks" that "complement markets and hierarchies as governing structures for authoritatively allocating resources and exercising control and coordination" (Rhodes, 1996, p. 652). The idea that markets, networks, and hierarchies are the constituent parts of social life is generally accepted in social science (Dahl \& Lindblom, 1963; Thompson et al., 1994), but it is less clear how these coordination mechanisms theoretically relate to governance. One way of dealing with this problem is to conceptualize these coordination mechanisms as governance structures, where a governance structure might be treated as the institutional context of the interaction between public and private actors (Van Vught, 1995). This section elaborates on coordination systems as governance structures in two steps. First, the principal differences between the three coordination systems will be addressed briefly, and second, based on these differences, a notion of governance structure will be suggested with the help of institutional rules developed by Ostrom (1986). 


\section{Differences Between Coordination Systems}

In regard to the coordination of economic activities, ${ }^{1}$ it can be assumed that markets, networks, and hierarchies differ in three fundamental ways: (a) the mechanism of economic decisionmaking, (b) the mechanism of allocation, and (c) the goals of economic activities (Arentsen \& Künneke, 1996; see also Powell, 1994). Table 1 summarizes the argument.

\section{Table 1}

Characteristics of Basic Coordinating Systems

$\begin{array}{llll}\begin{array}{l}\text { Coordinating } \\ \text { Mechanism }\end{array} & \begin{array}{l}\text { Unit of } \\ \text { Decisionmaking }\end{array} & \begin{array}{l}\text { Mechanism of } \\ \text { Allocation }\end{array} & \begin{array}{l}\text { Dominant } \\ \text { Economic Goal }\end{array} \\ \text { Market } & \text { Individual } & \text { Price setting } & \begin{array}{l}\text { Individual } \\ \text { profitability } \\ \text { and continuity }\end{array} \\ \text { Network } & \text { Group } & \text { Agreement } & \begin{array}{l}\text { Individual } \\ \text { profitability } \\ \text { and continuity }\end{array} \\ & & & \begin{array}{l}\text { National } \\ \text { public interest }\end{array}\end{array}$

In a system of full market coordination, decisionmaking is completely individualized. Individual players, motivated by self-interest, are autonomous decisionmakers regarding their consumption and production of goods and services. The neoclassical price theory models this individual decision process with great formal elegance. Price setting governs the system, in which individual players compete against each other to achieve individual economic goals. The network is characterized by a voluntary collective decision process among a group of players. Although all the players have identical property rights with respect to certain economic goods, none of them is able to change or capitalize their bundle of property rights without the approval of the other members of the group. In a network, players decide to cooperate voluntarily; consensus-building becomes the primary mechanism for allocating goods and services. This reduces the degree of autonomy enjoyed by individual decisionmakers. The economic goals of the group can be described as collective profitability and continuity. The third mechanism for coordinating economic activity is the public authority. Here the decision mechanism is based on the public authority forcing actors to operate the system according to certain public goals, the dominant economic goal being not individual or collective profitability but the general public interest.

The three systems of coordination incorporate different opportunities to regulate. Based on the notion of principal agents, ${ }^{2}$ a relationship between institutional organization on the one hand and the position of public authorities and the style and object of regulation on the other, can be assumed. Table 2 summarizes the argument.

In market systems, a public authority is assumed basically to be subordinated by private actors and can take on only a facilitating role by 
guaranteeing certain structural preconditions for the autonomous functioning of the market. In network systems, a public authority is a member of a group of actors with no specific dominant or subordinate parties. Such an institutional context not only has a facilitating effect but also allows for the identification of specific objectives; public authority has to convince other parties by negotiation to adjust its goals. In hierarchical systems, a public authority is able to impose its own goals on private actors because of its dominant position within the system;

\section{Table 2}

\section{Institutional Organization and Regulation}

\begin{tabular}{llll}
$\begin{array}{l}\text { Institutional } \\
\text { Organization }\end{array}$ & $\begin{array}{l}\text { Position of Public } \\
\text { Authority }\end{array}$ & $\begin{array}{l}\text { Dominant Style } \\
\text { of Regulation }\end{array}$ & $\begin{array}{l}\text { Dominant Object } \\
\text { of Regulation }\end{array}$ \\
Market & Subordinate & Facilitating & Structure \\
Network & Equivalent & $\begin{array}{l}\text { Facilitating, } \\
\text { initiating }\end{array}$ & Conduct \\
Hierarchy & Dominant & $\begin{array}{l}\text { Facilitating, } \\
\text { initiating, and } \\
\text { enforcing }\end{array}$ & $\begin{array}{l}\text { Structure and } \\
\text { conduct }\end{array}$ \\
\hline
\end{tabular}

dependence on private actors is at a minimum. The type of institutional organization is assumed to determine the role of the public authority, and this role is assumed to dictate the style of public regulation. The style of public regulation is defined by the degree of coerciveness (Mitnick, 1980); in a pure hierarchical institutional organization this style is assumed to be coercive by definition, whereas in a neoclassical free market the style is as least coercive as possible.

To conclude, markets, networks, and hierarchies as basic systems for coordination of social life differ among (a) the kind of actors dominating the system, (b) the dominant goal orientation of these actors, and (c) the fundamental mechanism underlying the coordination. Furthermore, these three coordination systems are assumed to condition the ability and impact of public regulation, since the position and role of public authorities differ among the three systems. These differences among the three coordination systems can be taken as a point of departure to elaborate on the concept of governance structure.

\section{Governance Structure Defined by Institutional Rules}

Since governance structures manifes the interaction between public and private actors, the relationship between "structure" and "interaction" or "conduct" needs to be specified. Neoinstitutional theory might be helpful in exploring the logic of this relationship. One way of dealing with this relationship is to treat structures as systems of rules (Ostrom, 1986). Such a conceptualization expresses the notion that "rules are the result of implicit or explicit efforts by a set of individuals to achieve order and predictability within defined situations," (Ostrom, 1986 , p. 5) a notion that embodies institutionalization of (collective) decisionmaking. "Institutions are the rules of the game in a society, or more formally...the humanly devised constraints that shape human interaction" (North, 1990 , p. 3). Markets, networks, and hierarchies can be treated as "humanly 
devised constraints" or as institutions that specify a context for human action and interaction. To define the structure or context of an action situation, Ostrom suggests "seven broad types of rules that operate configurationally to structure an action situation" (Ostrom, 1986, p. 19). These rules $\operatorname{are}^{3}$ (a) position rules that specify a set of positions and how many participants hold each position, (b) boundary rules that specify how participants are chosen to hold these positions and how participants leave these positions, (c) scope rules that specify the set of outcomes that may be affected and the external inducements and/or costs assigned to each of these outcomes, (d) authority rules that specify the set of actions assigned to a position at a particular node, (e) aggregation rules that specify the decision function to be used at a particular node to map actions into intermediate or final outcomes, (f) information rules that authorize channels of communication among participants in positions and specify the language and form in which communication will take place, and $(\mathrm{g})$ pay-off rules that prescribe how benefits and costs are to be distributed between participants in positions.

In fact, these rules "structure" governance by defining the actors, the action situation, and the outcomes of the action. Position and authority rules address the actors; boundary, aggregation, information, and pay-off rules define the situation; and scope rules define the outcomes. This set of rules defines markets, networks, and hierarchies as governance structures. Table 3 lists the rules and suggested constituent parts to be addressed by each of these rules; ${ }^{4}$ it should be taken as a first attempt to conceptualize governance structures.

\section{Table 3}

\section{Governance Structures and Their Defining Rules}

\begin{tabular}{|c|c|c|c|}
\hline & $\begin{array}{l}\text { Markets } \\
\text { (Structures } \\
\text { Inducing } \\
\text { Competition) }\end{array}$ & $\begin{array}{l}\text { Networks } \\
\text { (Structures } \\
\text { Inducing } \\
\text { Cooperation) }\end{array}$ & $\begin{array}{l}\text { Hierarchy } \\
\text { (Structures } \\
\text { Inducing } \\
\text { Authorization) }\end{array}$ \\
\hline Position rules & Property rights & Membership & Addressee \\
\hline Boundary rules & Contracts & Voluntarism & Legalism \\
\hline Scope rules & Private interest & Common interest & Public interest \\
\hline Authority rules & Exchange & Communication & Submission \\
\hline Aggregation rules & Prices & Agreement & Directive \\
\hline Information rules & Demand and supply & Cooperation & Legal restriction \\
\hline Pay-off rules & Efficiency & Legitimacy & Effectiveness \\
\hline
\end{tabular}

Comparison of Table 1 and Table 3 reveals the ability to transform the three coordination systems-market, network, and hierarchy-conceptually in three main types of governance structures with the help of the rules suggested by Ostrom to define institutions. Actually, Ostrom's rules provide a proper basis to understand the conceptual differences between the three main types of coordination systems, since one of the main criticisms in using the three systems is the inability to distinguish them at the conceptual level (see e.g., Powell, 1994). However, Ostrom's rules can be taken as a starting point to elaborate on their distinctive logic in spite of their intermingling in structuring the institutional 
organization of economic life in reality. A first step in analyzing this institutional complexity is to grip the logic of each of the models separately.

Competition is the dominant mode of interaction induced by marketbased structures. The set of rules defining this "action situation" is listed in the first column of Table 3 . First, actor positions are defined basically by (rules on) property rights. Those having no possession of property rights or the ability to obtain such rights are excluded from interaction. Only the have's and those willing and able to obtain property rights interact. Second, contracts-formal and informal-constitute the boundary of this institutional system, since exchange of property rights is organized in contracts, basically as bilateral contracts between buyer and seller. Third, all interactions have one principal scope: private interest, forcing all actors to be as rational as possible exchanging property rights. Fourth, exchange can be assumed to be the basic feature of the interaction between actors. Fifth, individual decisionmaking is based on prices and price rates, and decisive for the attainment of intermediate or final outcomes in exchange processes. Sixth, information on demand and supply underlies the whole system of exchange and is decisive for the willingness to interact. Last, cost-efficiency is the ultimate standard for all interactions taking place in a competitive institutional setting. Suppliers and demanders jointly are forced to be efficient in safeguarding continuity of position and interaction.

Interactions resulting from structures inducing cooperation are assumed to differ fundamentally from interactions resulting from structures inducing competition. In the former set of structures, positions are taken and hold on the basis of a voluntary membership of actors. Here, the scope of interaction is the common interest of the participating actors, since joint interest-seeking is assumed to be the dominant motivation for membership. The interaction is assumed to consist basically of communication of actor's ideas and (normative) views. Interactions will end and be decided by agreement, based on the "information rule" of cooperation. Without cooperation such a voluntary setting is hardly able to obtain outcomes, and in the end the functioning and outcomes of the system ought to be legitimate, an ultimate condition for the continuation of cooperation (Axelrod, 1984).

The rules suggested by Ostrom also distinguish a third set of structures, inducing authorization. The rationale of this institutional model is summarized in the third column of Table 3 . In this model positions are prescribed legally, and legalism determines positions as addressees. The scope is directed toward the general public interest, and interaction dominantly consists of submission by addressees. Directives are the basis of interactions, and information exchange is geared by legal restriction. Effectiveness of authorization can be assumed to be the ultimate payoff in this model.

The seven rules suggested by Ostrom seem to be most helpful in defining and distinguishing three main types of governance structures conceptually. However, the conceptualization suggested in this section should be taken only as a first start to be able to understand the empirical complexity of governance structures in reality, since the empirical world reveals structures consisting of (complex) combinations of the three models (Thompson et al., 1994). Environmental policies are initiated, formed, and implemented in the context of these structural complexities; at least they are in the Netherlands. Therefore, a proper understanding of the logic of environmental governance in the Netherlands should start with a closer look at the ability of each of the models to deal with environmental issues separately. 


\section{Logic of Environmental Governance in the Netherlands}

Table 3 helps to elucidate the different logic underlying each of the three governance structures for achieving environmental goals. Assuming rational actors and environmental goals to be public goals that conflict with private (economic) interests, only authoritative structures appear to be effective in achieving these goals. As can be seen from Table 3, authoritative structures define "action situations" in which private actors are subordinated to public authorities. These structures enforce environmental goals, optimizing environmental effectiveness at the expense of efficiency and legitimacy. On the other hand, competitive structures focus primarily on private interests as a result of private property rights, and so environmental goals will be achieved only if the efficiency criterion is met. Efficiency should be understood in terms of cost effectiveness for a private owner of property rights, so in theory environmental goal attainment in competitive structures will be achieved primarily by inducing cost-effective environmental measures. Both extreme models-competitive and authoritative structures-embody a dilemma in optimizing environmental performance, since competition allows environmental goals to be achieved only within the limits set by economic efficiency, whereas authoritative structures optimize effectiveness at the expense of efficiency and legitimacy. In competitive structures, legitimacy ceases to be a problem as long as the efficiency criterion is met.

Structures inducing cooperation might provide an alternative means to overcome the problems inherent in both competitive and authoritative governance. However, cooperation seems to embody the problem of effectiveness, faced by authoritative governance and the difficulty of being efficient faced by competitive governance. As Table 3 illustrates, the noncommittal logic underlying this type of governance makes it very fragile. Unlike both other models, cooperation does not produce an economic (property rights) or legal (addressee) need to participate in the game. It does not embody an endogenous "force" for commitment. However, participation by private actors might be induced by conviction or enforcement, for example, by threatening restrictive legal measures that might suggest cooperation to avoid these unfavorable measures. But willingness to cooperate should not be taken as an actor's willingness to increase its environmental performance; indeed, the scope rule of cooperation is a barrier to achieving significant results. The scope should reflect group interest, and in case of environmental goals will embody conflicting interests. Setting and achieving environmental goals should be manifested in the group interest promoted by public authorities, whereas private actors promote the maintenance and continuation of private economic goals. As a consequence, group interest is almost by definition a compromise if environmental issues are to be dealt with by cooperation. This compromise is strengthened by the rules governing cooperation: the authority rule (communication), the aggregation rule (agreement), and the information rule (cooperation). Conflicting interests prevent cooperative governance from leading to shared outcomes (group interests) as long as the pay-off rule does not meet the criterion of legitimacy. ${ }^{5}$ If this criterion is not met, interaction between private and public actors on environmental issues will break down before agreement can be reached on shared outcomes. Cooperative governance, therefore, is driven by a logic that results in legitimate rather than efficient or effective outcomes. When 
applied to environmental governance, cooperation forces public authorities to take account of private economic interests for the sake of effectiveness.

To conclude, achieving environmental goals seems to be most effective using a combination of the three modes of governance identified above. It is assumed that this logic underlies negotiated governance in the Netherlands, and its results can be explained properly only by its potential to find a dynamic balance between the effectiveness, efficiency, and legitimacy of enhancing environmental performance. Dutch-negotiated governance can be perceived as a circle of governance that meets the payoff incorporated in competitive, cooperative, and authoritative governance structures, improving the quality of the environment in an iterative process of different types of interactions between private and public actors (see Figure 1).

\section{Figure 1}

Dutch-Negotiated Governance as a Circle of Governance

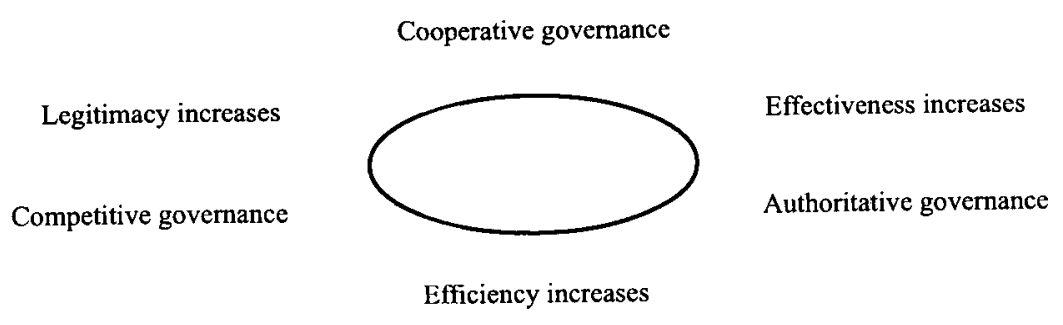

It should be noted that the circle represents neither a closed system nor a prescribed sequence. The circle only illustrates the logic underlying negotiated governance in the Netherlands. The process may start at any point, and the sequence in governance can differ among economic sectors. Dutch environmental policies, for example, started under an authoritative mode of governance in the 1970 s that was relieved by cooperative governance during the 1980s and 1990s as a reaction to the problems of legitimacy and efficiency. On the other hand, industrial energy efficiency policies were initiated through cooperation (see also the next section). Competitive governance is very limited in the Netherlands: there is an energy tax on electricity and gas but only for small consumers, and in some economic sectors such as agriculture, production and pollution rights operate on only a limited scale.

To conclude, negotiated governance in the Netherlands is not simply a matter of compromising environmental standards. Dutch-negotiated governance should be understood as a continuous process aimed at improving the environment by searching for trade-offs between private and public (environmental) goals, a process that can be understood as a circle consisting of three different modes of governance, each in a specific way contributing to the improvement of the 
environmental performance. The logic of the three models has been illustrated with the help of the seven rules of Ostrom defining an action situation. It turned out that competitive governance contributes by accounting for efficiency, cooperative governance for legitimacy, and authoritative governance for effectiveness. The intermingling functioning of these three modes of governance offers an attempt to understand the logic of Dutch-negotiated environmental governance. The next section illustrates the arguments by taking energy-saving policies and $\mathrm{CO}_{2}$ reduction in industry as an example.

\section{Energy Saving and $\mathrm{CO} 2$ Emissions Reduction Policies in the Netherlands}

Energy-saving policies in the Netherlands have developed in different stages, each manifesting a different mix of governance. The first stage, starting in the beginning of the $1970 \mathrm{~s}$, can be labeled as "the emergence of the problem," a period dominated by the first energy crisis and high energy prices. The second stage, starting in the early 1980s, can be summarized as "setting the agenda," a period during which energy prices were relatively low and environmental impacts of energy consumption were not at the top of the societal and political agenda. The last stage, "the big deal," starting in the early 1990s, was the period characterized by low energy prices and climate change policies on top of the political agenda. This section describes these different periods in energy-saving policy to illustrate the arguments on environmental governance made in former sections of this article.

\section{The Emergence of the Problem}

The first oil crisis, at the beginning of the 1970s, marked a change in the Dutch national energy policy. ${ }^{6}$ Before the crisis, Dutch energy policy was dominantly directed toward securing a constant supply of energy for the national economy. Extensive gas reserves in the northern part of the country covered the domestic need for natural gas, and imports, especially of crude oil, covered the need for other fuels and feedstock. Crude oil was imported from the Middle East, but in 1973, due to the Dutch position in the Yom Kippur war, imports were blocked. ${ }^{7}$ From 1975 on, oil prices increased steadily and prompted a policy change. In 1974, the Dutch government announced two changes in energy policy by introducing the two principles of diversification, to release dependence on oil imports from the Middle East, and energy savings, to a larger extent motivated by shortage of energy and high energy prices and to a minor extent motivated by environmental arguments.

As a part of this policy, the Dutch electricity industry, using domestic gas as the basic fuel for electricity generation, was forced to change to coal, to save national gas reserves. Coal-fired generation was expanded to save oil and gas, raising $\mathrm{CO} 2$, sulfur dioxide ( $\mathrm{SO} 2)$, and nitrous oxide $(\mathrm{NOx})$. The Dutch government considered that additional measures would be necessary to meet Dutch air emission standards and the standards set by the EU directive on large combustion plants in preparation at that time. The electricity industry felt that this would increase the price of electricity to an unreasonable degree, and that the technology required to reduce emissions was not yet available (Rense \& ter Heide, 1988). The industry was able to resist change for several years, holding back investments in desulphurization, for example. In order to break down this resistance, the Dutch Government heavily subsidized research and development in 
new technology to enable the electricity industry to meet the NOx reduction targets.

During the 1970s and early 1980s, energy-saving policies for other branches of industry were primarily incentive-oriented. To encourage industrial investments in energy saving, the Dutch government introduced several subsidies, supporting investments in energy improvements up to $25 \%$. In the early $1980 \mathrm{~s}$, when the economic recession was at its deepest, credit measures were added, allowing industry to borrow money under favorable conditions. In spite of these supportive measures, industry invested for only a couple of years, since energy shortage was a problem for only a limited period of time during the $1070 \mathrm{~s}$. At that time, the economic recession heavily intervened energy saving policies in the Netherlands. At the beginning of the 1980s, the Dutch Parliament discussed taxes and regulatory measures to intensify industrial energy savings, but taxes were defeated for reasons of competitiveness of the Dutch industry, and regulatory measures were cached up by decreasing energy prices. The first episode in Dutch energy-saving policy ended with only some adjustments in national energy policy, especially on gas-depletion policy and diversification in energy resources. ${ }^{8}$ However, high energy prices in combination with policy efforts had some impact on energy saving in industry. Between 1980 and 1985 industry improved its energy efficiency with $1.9 \%$ annually and between 1985 and 1988 with $1.1 \%$ annually. After 1985, efficiency improvements decreased due to lower world energy prices and because obvious and relatively cheap options to save energy became rare. ${ }^{9}$ Although energy savings were primary motivated by a shortage of energy and high prices, the first period also introduced some of the environmentally based energy-saving vocabulary that became dominant in later periods.

\section{Setting the Agenda}

By the end of the 1980 s, energy prices fell, frustrating the need to save energy, which started to enter the political agenda at that time. This time the need to decrease national energy consumption was also environmentally motivated, especially the need to decrease $\mathrm{CO}$-emissions. It became one of the basic arguments to motivate and legitimize energy-saving politics. In 1989 the Dutch government presented its first nationwide integrated environmental program, offering a first attempt at integrated problem analysis and problem solving. Energy-saving targets were part of this environmental program and were documented separately in a White Paper on Energy, for the first time titled A White Paper on Energy Saving.

The national environmental program and the White Paper on Energy Saving were innovative in respect to the attempt to integrate the rather differentiated and fragmented environmental and energy-saving policies at the level of target groups. Target groups were, for instance, branches of industry, transport, agriculture, power generators, households, and the like. The White Paper listed energy-saving targets for each of these groups separately, motivated and legitimized by the need to reduce $\mathrm{CO}_{2}$ emissions to release problems like climate change and the acidification of the environment, which started to enter and dominate the national and international political agenda at that time. From that time on the theme of climate change has made the improvement of energy efficiency one of the central issues of the national environmental program, in spite of low energy prices. Table 4 lists the development of the main targets for the years up to $2000 .{ }^{10}$ 


\section{Table 4}

\section{Dutch Goals for Energy Efficiency}

\section{Program and Update}

White Paper on Energy

efficiency 1990

First update in 1993

Second update in 1995

Actual improvement since 1990

\section{Targets and Update}

$2 \%$ reduction annually between 1990 and 2000

$1.7 \%$ reduction annually between 1990 2000

$1.6 \%$ reduction annually until 2000

$1.1 \%$ annual energy savings

Energy consumption in 1989 is taken as the reference level for the reduction targets. Table 4 illustrates a decline in the ambitions of policy for saving energy, mainly in recognition of the low energy prices. Since 1990 the actual annual energy savings of $1.1 \%$ in relation to 1989 has lagged behind stated policy goals. So from 1989 on, energy saving entered the policy agenda step by step, during the 1990s supported by the international dialogue on climate change. As a result, the focus in Dutch energy policy was redirected towards energy conservation, energy efficiency, and sustainable energy resources, and cooperative governance steadily entered and dominated the level playing field of energysaving policies.

\section{The Big Deal}

From the beginning of the 1990s, national energy-saving policy was strongly supported by the international debate on climate change. From that time on energy saving became a serious policy issue in Dutch society. The first national environmental program marked a point of no return in Dutch energysaving policy, challenging every sector of the Dutch economy to save energy. The Ministry of Economic Affairs, first responsible for energy policy and energysaving policy, introduced a cooperative mode of governance to enhance energy saving in industry. Central in this policy was the so-called long-term agreement on energy saving, an agreement in which industry committed itself to energysaving goals of 20 to $30 \%$ by the year 2000 in comparison with 1989 . In return, industry was supported financially in research and development.

The main target of the long-term agreement was to improve the industrial energy efficiency without affecting domestic economic growth rates or the position of the Dutch industry in (international) competition. So the agreements account for economic interests of industry, since the agreed targets account for technological and economic-saving potentials, and industry is allowed to implement very flexible saving measures. According to the Dutch Ministry of Economic Affairs, the agreements were successful. Between 1992 and 1998 the Ministry agreed upon long-term energy savings with 29 industrial sectors. In 1994,18 economic sectors, representing about $73 \%$ of annual domestic industrial energetic energy consumption, achieved a reduction in energy consumption of $9 \%$ compared with 1989. The improvement in 1994 compared with 1993 was 3\%, 
mainly due to energy savings made by the Dutch chemical industry, the most energy-intensive industry in the Netherlands (Ministry of Economic Affairs, 1996). Figures of 1996 show a further improvement of energy efficiency to $12.5 \%$ in comparison with 1989 . The 1996 figures are based on 26 agreements, accounting for $90 \%$ of the energetic industrial energy consumption (Ministry of Economic Affairs, 1997b, p. 4).

This type of cooperative governance is open for all industry, but concentrates on industries using at least one Peta Joule (PJ) of energy annually and able to meet some additional conditions. Industries open for an agreement should be rather homogenous in products and processes, should be well organized as a group, able and willing to commit to implement the agreed targets, and the number of participating firms should account for at least $80 \%$ of the overall energy consumption of the sector. Industry not able to meet these conditions, mainly small- and medium-sized business, is excluded from an agreement. Energy saving by small business is separately dealt with by different measures, fitting in all three modes of governance. Part of the energy-saving policy for small business is an agreement with the Dutch energy industry aimed at reducing emissions of $\mathrm{SO} 2, \mathrm{NOx}$, and $\mathrm{CO}_{2}$ by $1990 .{ }^{11}$ The agreement committed the energy industry to emission levels of 18,000 tons of $\mathrm{SO}_{2}$ and 30,000 tons of NOx by the year 2000 . The energy distributors committed themselves to initiating and enhancing energy efficiency by end users. ${ }^{12}$ As a result of this agreement, the distributors of energy developed an extensive program on energy saving by small industrial and private energy consumers, a program financed by the consumers themselves by means of an energy levy per $\mathrm{kWh}$. Energy saving by small industry is basically initiated by financial support of research and development.

Apart from these supportive measures, additional incentive- and authoritative-based measures were taken to stabilize $\mathrm{CO}_{2}$ emissions. In 1996 an energy charge for small industrial energy users was introduced. Giant industrial users were exempted for reasons of competition. Furthermore, fiscal measures and subsidies for investments in energy conservation techniques and research and development (R\&D) into efficiency improvements and "green technologies" have been introduced. In 1993, energy efficiency standards were incorporated into the environmental permit for industrial activities. Firms participating in a long-term agreement on energy saving are treated differently from firms not participating in such an agreement. The legal obligations for firms participating in an agreement are far less restrictive and much more flexible than for firms not committed to such an agreement. So participation in a long-term agreement is also rewarding in regard to legal obligations of environmental laws. Companies approving their environmental and energy management are significantly rewarded by being issued a so-called "flexible" environmental permit. These permits contain the targets the company has to meet without prescribing detailed measures. Private companies can cooperate by exchanging good management and housekeeping practices while being subjected to less direct public authority involvement in the environmental performance of the company, increasing their level of autonomy and degree of flexibility in decisionmaking. As a consequence, the company gains efficiency in terms of environmental performance.

To conclude, in spite of low energy prices, cooperative governance has resulted in a number of agreements with industry on energy conservation. The process of reaching agreement reveals the noncommittal characteristic of this mode of governance. The energy efficiency potential documented in the agreements is heavily influenced by industry, and there is still uncertainty about 
the ability to meet objectives. For this reason, progress in reaching the stated goals at the company level is linked to the ability of the environmental permit to reward companies for progress made with energy efficiency and to punish for relapses.

This section tentatively illustrated negotiated environmental governance in the Netherlands with respect to energy saving and $\mathrm{CO}$-emmission reduction. Between early 1970s and late 1990s, the mixture embodied in negotiated environmental governance was applied using the economic and societal opportunities to decrease industrial energy consumption. During the 1970s, industrial energy conservation was basically supported by incentive-based governance and legitimized by high energy prices and the need to protect the national economy. In spite of high energy prices endogenously stimulating saving investments in industry, public subsidies were added to overcome the threats of high energy prices and to protect the national economy. As a result, industrial energy efficiency indeed improved during those years. The finiteness of obvious cost-effective investments in combination with decreasing world energy prices deprived energy conservation policies of economically motivated legitimization by the end of the 1980s. The environmental impact of energy consumption, especially the hazardous impact of $\mathrm{CO} 2$-emmission, provided the new basis for energy-saving policies. However, industry missing economic incentives and therefore not enthusiastic about the strengthening of energy-conservation targets had to be challenged by offering cooperation as target groups. The dialogues between government and the target groups locked industry in policy formation and policy implementation. Industry became committed to the policy targets, but was offered responsibility, flexibility, and financial support in return, in order to attain of the reduction efforts agreed upon. This mode of governance not only turned out to be promising and effective, but also initiated tailor-made policies for target groups, resulting in policies that accounted for sector-specific opportunities and hindrances to save energy and to reward progress in savings and to "punish" delay and obstruction. Firms lagging behind in saving efforts had to face legal obligations. The environmental law allowed for individual energy quality standards in environmental permits. However, the agreements also initiated processes of social control within industrial branches, because the branch as a whole jointly commits to the agreement, sharing the agreed efforts among individual firms. Delay and obstruction by one firm automatically increases the burden for other firms. This turns out to be an autonomous drive to keep individual efforts within the branch in balance. So negotiated environmental governance also initiates spin-offs to contribute more indirectly and autonomously to improvement of the environment.

\section{Conclusions}

In the introduction of this article it was stated that non-Dutch often wonder about the Dutch way of handling environmental problems in a rather noncommitting way. This article has illustrated how this seemingly "voluntary" mode of governance actually consists of a mixture of three strategies, each contributing in a specific way to environmental goal attainment. The underlying institutional logic of each of these strategies can be illuminated with the help of the institutional rules suggested by Ostrom. It turns out that the voluntary way of environmental policymaking in the Netherlands actually incorporates an iterative mixture of different policy strategies, integrating voluntarism, incitement, and 
enforcement. This mixture of strategies has been illuminated at the analytical level, as a circle of governance searching for effective, efficient and legitimate policy outcomes. This mixture of governance, rooted in the Dutch tradition of corporatism, allows for an exchange of different opinions and interests and to deal with environmental issues by dialogue, negotiation, and compromise, but, if necessary, also by economic and regulatory enforcement. This mixture of strategies as well as the timing of its application contributed to the improvement of energy efficiencies of larger parts of the Dutch industry.

This Dutch mode of environmental governance is not performing significantly better or worse than European average, but in the Dutch context it is a necessary condition to perform. It is the responsiveness incorporated in this mode of governance that turned out to be worthwhile and productive. In an environment full of differentiated and often conflicting interests, has long been the case in the religious and socioeconomic tensions of Dutch society, responsiveness turned out to be a prerequisite to governing. This has been the major lesson of Dutch postwar corporatism and is now redesigned for and adopted in environmental policies in the Netherlands. Responsiveness presupposes openness of policy processes and commitment to policy outcomes. If these conditions are met, Dutch environmental governance provides an inspiring alternative for environmentally related policy processes blocked by conflicting interests and frustrated by a lack of productive policy outcomes and effective policy effects. So the specificity of Dutch-negotiated environmental governance is not its ability to perform better in regard to others, nor its ability to initiate environmental improvements in a noncommitting way. The real "secret" of Dutch environmental governance is its ability to cope with conflicting interests without a decrease in real improvement of environment quality. In a society full of tensions, the Dutch have learned to be pragmatic, and this is basically reflected in Dutch-negotiated environmental governance. Attaining the desirable by going for the attainable: making and taking opportunities to improve the environment by competitive governance if allowed, cooperative governance if needed, and authoritative governance if necessary.

Maarten J. Arentsen is a senior researcher and vice-director of the Center for Clean Technology and Environmental Policy of the University of Twente in the Netherlands. His research focuses on energy and environmental policy and management, with emphasis on institutional organization and change, regulation, and innovation.

\section{Notes}

\footnotetext{
${ }^{1}$ Since environmental policy is primarily aimed at goal attainment by influencing the economic process, I concentrate on the coordination of economic life.

${ }^{2}$ The argument is based on the notion of information exchange and the consequences of information asymmetry for effective regulation.

${ }^{3}$ The rules are taken literally from Ostrom, 1986, p. 19.

${ }^{4}$ These three institutional settings partly repeat and exceed the previous argument in terms of coordination mechanisms.

${ }^{5}$ The argument is given by Axelrod's principle of reciprocity: a folkway that involves helping out a colleague and getting repaid in kind (Axelrod, 1984, pp 124-141).

${ }^{6}$ The content of this section is largely taken from van den Doelen, 1989.
} 
${ }^{7}$ In 1974 , about $45 \%$ of the overall Dutch energy consumption depended on oil imports. The oil crisis also affected the Dutch oil transition industry, which was and is very significant in the Dutch economy. In 1974 about 20 to $25 \%$ of the oil consumed in the European Community was imported via and refined in Rotterdam harbor.(White Paper on Energy, p. 30-31)

${ }^{8}$ Part of that discussion was the establishment of a nuclear program.

${ }^{9}$ Ministry of Economic Affairs, White Paper on Energy Saving, p. 113.

${ }^{10}$ Figures in this section are taken from RIVM, 1996.

${ }^{11}$ Dutch Government Gazette, 1992, p. 451.

${ }^{12}$ On the whole, this action program has only been partially successful, because the energy efficiency of Dutch small businesses lags behind other countries (see EnergieNed, 1991, 1994, 1996).

\section{References}

Arentsen, M. J., \& Künneke, R. W. (1996). Economic organization and liberalization of the electricity sector: In search for conceptualization. Energy Policy, 24(6), 541-552.

Axelrod, R. (1984). The evolution of cooperation, New York, NY: Basic Books.

Dahl, R. A., \& Lindblom, C. E. (1963). Politics, economics, and welfare. New York, NY: Harper and Row.

Dutch Government Gazette. (1992). Dutch Government Gazette. The Hague: SDU Publishers.

EnergieNed. (1991). Environmental program of energy distributors (in Dutch). Amhem: Author.

EnergieNed. (1994). Environmental program of energy distributors (in Dutch). Amhem: Author.

EnergieNed (1996). Results of the environmental program of energy distributors 1995 (in Dutch). Arnhem.

March, J., G., \& Olsen, J. P. (1995). Democratic governance. New York, NY: The Free Press.

Ministry of Economic Affairs. (1990). White paper on energy saving. The Hague.: SDU Publishers.

Ministry of Economic Affairs. (1996). Long term agreements on energy efficiency: Results 1994 (in Dutch). The Hague: SDU Publishers.

Ministry of Economic Affairs. (1997a). Energy in the Netherlands (in Dutch)). The Hague: SDU Publishers.

Ministry of Economic Affairs. (1997b). Long term agreements on energy efficiency: Results, 1996. (In Dutch). The Hague: SDU Publishers.

Mitnick, B. (1980). The political economy of regulation. New York, NY: Colombia University Press.

North, D. C. (1990). Institutions, institutional change, and economic performance. Cambridge, MA: Cambridge University Press.

Ostrom, E. (1986). An agenda for the study of institutions. Public Choice, 4(1), 3-25.

Powell, W. E. (1994). Neither markets nor hierarchies: Network forms of organization. In J. Thompson, F. R. Levacie, \& J. Michel (Eds.), Markets, hierarchies and networks: The coordination of social life (pp. 265-277). London: Sage.

Rense, R., \& ter Heide, F. J. (1988). Evaluation environmental policy electricity generation (in Dutch). Twijnstra Gudde NV: Deventer.

Rhodes, R. A. W. (1996). The new governance: Governing without government. Political Studies, XLIV, 652-667.

RIVM, Rijksinstituut voor Volksgezondheid en Milieu. (1996). Environmental Balance 1996, Alphen aan den Rijn (in Dutch). Samson tjeenk Willink.

Thompson, J., Levacie, F. R., \& Michel, J. (Eds.). (1994). Markets, hierarchies and networks. The coordination of social life. London.

van den Doelen, F. (1989). Policy instruments and energy saving (in Dutch). Ph.D. dissertation. Enschede.

van Vught, F. (1995). Governance structures in higher education. NIG working paper no. 95-3. Enschede.

van Waarden, F. (1992). The historical institutionalization of typical national patterns in policy networks between state and industry: A comparison of the USA and the Netherlands. European Journal of Political Research, 21(1-2), 131-163. 